Original Research Paper

\title{
Critical Success Factors of Information Technology Outsourcing for Emerging Markets
}

\author{
${ }^{1}$ Sushil Paudel and ${ }^{2}$ Vinish Kumar \\ ${ }^{1}$ Mewar University, Rajasthan, India \\ ${ }^{2}$ SANSKAR College of Engineering and Technology, Gaziabad, India
}

\author{
Article history \\ Received: 18-02-2021 \\ Revised: 25-03-2021 \\ Accepted: 27-03-2021 \\ Corresponding Author: \\ Sushil Paudel \\ Mewar University, Chittorgarh, \\ Rajasthan, India \\ Email: sushilpaudel@gmail.com
}

\begin{abstract}
Outsourcing has gained popularity as several large U.S. companies in the $1980 \mathrm{~s}$ began delegating IT work to foreign firms. In outsourcing, one party (customer) asks another party (vendor) to do a particular job. Outsourcing has its own advantages, like reducing the cost and time and increasing performance and satisfaction. This study has focused on the critical success factors in information technology outsourcing for the emerging market and has considered the perspectives of the vendor. A snowball sampling technique was used to generate quantitative data among the respondents inside Kathmandu valley and variables were drawn from the available literature. Respondents included outsourcing vendors, freelancers, consultants and policymakers. Data were properly tested for reliability using Cronbach's Alpha and results were validated using convergent and discriminant validity. The analysis included Structured Equation Modeling and Estimation was done using maximum likelihood and partial least squares. The study identified 21 critical success factors for the emerging market under seven categories: System quality, communication quality, service quality, system use, satisfaction, individual benefit and organizational benefit which is the main contribution of the paper. It is suggested that IT outsourcing vendors focus on these factors, policymakers implement new strategies to establish their presence in global outsourcing industries and researchers incorporate these variables in their future research.
\end{abstract}

Keywords: Critical Success Factors, Information Technology Outsourcing, Maximum Likelihood, Partial Least Squares, Structured Equation Modelling

\section{Introduction}

Outsourcing has become one of the study areas for various fields in the shifting global marketplace (Aksoy et al., 2014). The outsourcing of information technology is an unavoidable part of modern enterprises (Bapna et al., 2010), growing at an average of $4.4 \%$ since 2010 (Gartner, 2020). Outsourcing enables companies to concentrate on their core business and assigns non-critical roles to other companies with proven capabilities. In other words, the use of logistic services by third-party organizations is seen as outsourcing (Erturgut, 2012). Outsourcing is considered to be one of the best drivers of economic development.

Information and Communication Technology (ICT) is one of the fastest-growing sectors in Nepal, including the internet, telephone, mobile, Information Technology Enabled Services (ITES) and Business Process Outsourcing (BPO). Nepal Government has identified
ITES and BPO as one of the five export potential services targets (Investment Board Nepal, 2017).

The export of ICT services from India amounted to 78.5 billion US dollars and China to 25 billion US dollars (excluding manufacturing) in 2017, with a significant contribution to their GDP. During the same period, Nepal exported services amounting to 287 million, much lower than its neighboring countries (World Bank Group, 2018). Kearney (2017) shows that India is the most preferred location for outsourcing services, followed by China, Malaysia, Indonesia, Brazil, Vietnam, Philippines, Thailand, Chile and Colombia. Similarly, Sri Lanka, Poland, Mexico, Egypt, Bulgaria, Czech Republic, Germany, Romania and UK are some of the other successful countries. However, countries like Nepal are still at an emerging stage and struggling to make their presence felt on the international market. Therefore, the purpose of this article is to evaluate the critical success 
factors of IT outsourcing and to identify study variables for emerging markets, in particular Nepal, from the vendor's perspective.

There were three research questions for the study. Q1: What are the critical success factors of information technology outsourcing on a vendor's perspective? Q2: What are the strategies to promote IT outsourcing services in the emerging countries? Q3. What would be the appropriate ITO Success Model for IT outsourcing vendors? This paper is presented based on Q1 with an objective to identify the critical success factors of information technology outsourcing for an emerging market, especially Nepal, as a global vendor.

\section{Research Methodology}

This is an exploratory study based on quantitative data. The study was carried out in 3 districts, viz., Kathmandu, Lalitpur and Bhaktapur, inside Kathmandu valley, the capital city of Nepal. IT outsourcing companies, freelancers, outsourcing experts and public officials were statistical populations. The sample size was 385 and a structured questionnaire was used as an instrument. The questionnaire was designed in 5-point Likert Scale starting from 5 (Strongly Agree), 4 (Agree), 3 (Neutral), 2 (Disagree) and 1 (Strongly Disagree). The questionnaire contained 70 variables and was distributed to 10 subject experts for content validity.

Urbach and Muller (2012) identified numerous variables for Information Systems Success on a systematic literature review based on the research works carried out by (DeLone and McLean, 1992; 2003; Bailey and Pearson, 1983; Gable et al., 2008; Iivari, 2005; Rainer and Watson, 1995; McKinney et al., 2002; Doll and Torkzadeh, 1988; Chang and King, 2005; Pitt et al., 1995; Almutairi and Subramanian, 2005). All observed and unobserved variables (Table 1) were selected from the literature review based on the works of the above authors and variables were validated with the industry experts.

\section{Data Collection}

In Nepal, companies are registered in the Office of the Company Registrar. IT companies are classified in the categories as per the international industrial code, e.g., software development and consultancy (industrial code: 7220), database activities and distribution of electronic content (7240), hardware repair and maintenance (7250), data processing (7230), hardware consultancy (7210) and Other IT activities (7290). However, there is no separate industrial code assigned for IT outsourcing and this made it difficult to identify the actual population. As per (Investment Board Nepal, 2017), there are over 6,000 BPO businesses, of which only 256 are legally registered in Nepal. The snowball sampling approach was adopted to reach new respondents based on a previous recommendation. Respondents were also identified using individual contacts and web searches. A structured questionnaire was designed in both English and Nepali languages. Prior approval or consent was obtained from each office/individual prior to the study and the information of the respondent was kept confidential on ethical grounds.

The questionnaire was distributed by the researcher personally, by using an enumerator and by email. Out of 590 questionnaires distributed, 403 questions were collected and upon removing missing and unusual records, 385 respondents were finally selected. The number satisfies the sample size for unknown population using the formula $\left.\mathrm{n}=\left(\mathrm{z}^{2} * \mathrm{p} * \mathrm{q}\right) / \mathrm{e}^{2}\right)$ where $\mathrm{z}=1.96$ at $95 \%$ confidence level, $\mathrm{p}=$ standard deviation $=0.5$ (maximum variability of the population at $50 \%$ ), $\mathrm{q}=1-\mathrm{p}$, $\mathrm{e}=$ margin of error $(0.05)$.

Table 1: The variables with their descriptions used in the present study

\begin{tabular}{ll}
\hline Latent variable & Description \\
\hline System quality & $\begin{array}{l}\text { The success variable system quality is concerned with system performance, reliability, user interface, } \\
\text { consistency, data accuracy, data currency, response time, efficiency, flexibility, integration capabilities, } \\
\text { features, update capability etc., of hardware or software system. A total of 17 success factors was used } \\
\text { in the research. } \\
\text { Communication quality relates to timeliness of communication, the accuracy of information, relevance, } \\
\text { reliability and scope of information being communicated between the customer and the vendor or vice } \\
\text { versa. A total of } 12 \text { success factors were selected for the research. }\end{array}$ \\
The success dimension of service quality represents the quality of the service that the customer receives \\
from the vendor, e.g., product training, helpdesk support, response time, resolution period, interpersonal \\
skills etc. A total of 9 success factors was selected from the literature review.
\end{tabular}


Ahmad Al-Jarrah et al. / Journal of Computer Science 2021, 17 (5): 459.469 DOI: 10.3844/jessp.2021.459.469

Table 2: Result of reliability, adequacy and sphericity test

\begin{tabular}{|c|c|c|c|c|c|c|c|}
\hline \multirow[b]{2}{*}{ Latent variable } & \multicolumn{3}{|c|}{ Reliability statistics } & \multirow{2}{*}{$\begin{array}{l}\text { KMO } \\
\text { measure of } \\
\text { sampling } \\
\text { adequacy } \\
\end{array}$} & \multirow{2}{*}{\multicolumn{2}{|c|}{$\begin{array}{l}\text { Bartlett's test of sphericity } \\
\begin{array}{l}\text { Approx. } \\
\text { chi-square } \quad \text { df }\end{array}\end{array}$}} & \multirow[b]{2}{*}{ Sig } \\
\hline & $\begin{array}{l}\text { Cronbach's } \\
\text { alpha }\end{array}$ & $\begin{array}{l}\text { Alpha based on } \\
\text { standardized items }\end{array}$ & $\mathrm{N}$ & & & & \\
\hline System quality & 0.837 & 0.858 & 17 & 0.650 & 3708.342 & 136 & 0.000 \\
\hline Communication quality & 0.901 & 0.914 & 12 & 0.822 & 3238.889 & 78 & 0.000 \\
\hline Service quality & 0.865 & 0.880 & 9 & 0.784 & 2099.577 & 36 & 0.000 \\
\hline System use & 0.803 & 0.803 & 4 & 0.664 & 664.607 & 6 & 0.000 \\
\hline Individual benefit & 0.855 & 0.855 & 5 & 0.830 & 820.648 & 10 & 0.000 \\
\hline Organizational benefit & 0.916 & 0.917 & 15 & 0.777 & 3851.038 & 105 & 0.000 \\
\hline
\end{tabular}

\section{Data Validation}

The data collected from respondents were checked for reliability. Reliability coefficient, Cronbach $\alpha$ was used for checking the reliability of the data. The questionnaire consisted of 70 observed variables divided into seven latent variables: System quality, service quality, communication quality, satisfaction, system use, individual benefit and organizational benefit. Cumulative Cronbach $\alpha$ was found to be 0.958 and the value suggests that the instrument is reliable. A reliability test of individual factors was also conducted, which ranged from 0.803 to 0.916 (Table 2). Since the coefficient of all the factors is above 0.7, the data was considered reliable for further analysis.

The Kaiser-Meyer-Olkin (KMO) measure of sampling adequacy and Bartlett's test of sphericity was conducted on each latent variable and observed the values between 0.65 and 0.83 , which is considered strong (> 0.6) for further study and considered suitable to explore the underlying attributes by using factor analysis. Bartlett's test of sphericity was highly significant $(p=000)$ for all variables, which rejects the null hypothesis and shows that the described attributes are correlated within the population.

\section{Analysis}

The data were analyzed using factor analysis, which is a procedure generally used for data reduction and summarization. When the number of variables is large, most of them may be highly correlated and factor analysis reduces such variables to a manageable level for interpretation. The study has utilized Confirmatory Factor Analysis (CFA) to identify the critical success factors. The data are presented under the following sub-headings.

\section{Single Factor Structural Equation Modeling}

From a conceptual standpoint, Structural Equation Modeling (SEM) analysis typically follows a positivist epistemological belief. In this vein, SEM arises from the fusion of two traditions. On the one hand, a psychometric approach (linear regression models), on the other - factor analysis. SEM thus incorporates the use of latent (unobserved variables) describing theoretical principles and measures data for statistical analysis (indicators or manifest variables used as inputs), providing proof of the relationships between latent variables. SEM is especially useful in Information Systems Research, where many, if not most, main concepts cannot be directly observed. Indeed, in recent years, a significant part of IT research has mainly used SEM as an empirical methodology for theory testing (Roldan and Sanchez-Franco, 2012).

Confirmatory factor analysis was performed in IBM SPSS AMOS, Version 26. Single-factor model was plotted separately for each of the latent variables and variables with factor loading less than 0.7 were eliminated except when the variables were tightly correlated with latent variable and removal of such variable would break the model. For estimation, covariance supplied as input was 'unbiased' and covariances to be analyzed was 'maximum likelihood' with an iteration limit of 50 (Tables 3-9, Figs. 1-7).

Table 3: List of observed variables under system quality and their factor loadings

\begin{tabular}{llll}
\hline Observed variables & Factor loading & Observed variables & Factor loading \\
\hline Easy to Access [SYSTEM1] & 0.544 & System Reliability [SYSTEM10] & 0.528 \\
Easy to Use [SYSTEM2] & 0.368 & System Consistency [SYSTEM11] & 0.755 \\
Data Accuracy in the System [SYSTEM3] & 0.665 & System Completeness [SYSTEM12] & 0.798 \\
Data Currency in the product [SYSTEM4] & 0.536 & System Response time [SYSTEM13] & 0.578 \\
Easy to Learn the System [SYSTEM5] & 0.526 & System Turnaround time [SYSTEM14] & 0.544 \\
System Efficiency [SYSTEM6] & 0.405 & System Sophistication [SYSTEM15] & 0.354 \\
System Flexibility [SYSTEM7] & 0.823 & Data Duplication and Repetition [SYSTEM16] & 0.029 \\
System Integration [SYSTEM8] & 0.362 & System Features [SYSTEM17] & 0.296 \\
System Interactivity [SYSTEM9] & 0.406 & &
\end{tabular}


Table 4: List of observed variables under communication quality and their factor loadings

\begin{tabular}{llll}
\hline Observed variables & Factor loading & Observed variables & Factor loading \\
\hline Accuracy of Information [COMM1] & 0.540 & Reliability of Information [COMM8] & 0.621 \\
Adequacy of Information [COMM 2] & 0.593 & Scope of Information [COMM9] & 0.680 \\
Availability of Information [COMM3] & 0.830 & Timeliness of Communication [COMM10] & 0.812 \\
Completeness of Information COMM4] & 0.710 & Understandability of Information [COMM11] & 0.726 \\
Conciseness of Information [COMM5] & 0.771 & Uniqueness of Information [COMM12] & 0.446 \\
Consistency of Information [COMM6] & 0.579 & Usability of Information [COMM13] & 0.626 \\
Relevance of Information [COMM7] & 0.659 & & \\
\hline
\end{tabular}

Table 5: List of observed variables under service quality and their factor loadings

\begin{tabular}{llll}
\hline Observed variables & Factor loading & Observed variables & Factor loading \\
\hline Empathy [SERVICE1] & 0.338 & Service Timeliness [SERVICE6] & 0.671 \\
Responsiveness [SERVICE2] & 0.842 & Service Reliability [SERVICE7] & 0.718 \\
Service Flexibility [SERVICE3] & 0.790 & Customer Orientation [SERVICE8] & 0.552 \\
Interpersonal Quality [SERVICE4] & 0.792 & Tangibles [SERVICE9] & 0.715 \\
Intrinsic Quality [SERVICE5] & 0.642 & & \\
\hline
\end{tabular}

Table 6: List of observed variables under system use and their factor loadings

\begin{tabular}{llll}
\hline Observed variables & Factor loading & Observed variables & Factor loading \\
\hline Actual Use [USE1] & 0.383 & Intention to (re)use [USE3] & 0.734 \\
Frequency of Use [USE2] & 1.014 & Usage patterns [USE4] & 0.698 \\
\hline
\end{tabular}

Table 7: List of observed variables under Satisfaction and their factor loadings

\begin{tabular}{llll}
\hline Observed variables & Factor loading & Observed variables & Factor loading \\
\hline Adequate Satisfaction [SATISF1] & 0.569 & Information/communication satisfaction [SATISF5] & 0.639 \\
Effectiveness of Product and Service [SATISF2] & 0.671 & System Satisfaction [SATISF6] & 0.616 \\
Satisfaction due to Efficiency [SATISF3] & 0.715 & Overall Satisfaction [SATISF7] & 0.678 \\
Enjoyment [SATISF4] & 0.651 & & \\
\hline
\end{tabular}

Table 8: List of observed variables under Individual Benefit and their factor loadings

\begin{tabular}{llll}
\hline Observed variables & Factor loading & Observed variables & Factor loading \\
\hline Training and Development [IB1] & 0.758 & Decision Effectiveness [IB4] & 0.805 \\
Job simplification [IB2] & 0.785 & Task innovation [IB5] & 0.641 \\
Performance Increment [IB3] & 0.694 & &
\end{tabular}

Table 9: List of observed variables under Organizational Benefit and their factor loadings

\begin{tabular}{llll}
\hline Observed variables & Factor loading & Observed variables & Factor loading \\
\hline Business Process Enhancement [OB1] & 0.637 & Improved Decision Making [OB9] & 0.736 \\
Competitive Advantage [OB2] & 0.689 & Increased Capacity [OB10] & 0.503 \\
Cost Reduction [OB3] & 0.575 & Overall Productivity Increase [OB11] & 0.651 \\
Enhancement of Communication and Collaboration [OB4] & 0.659 & Overall Success [OB12] & 0.716 \\
Better Coordination [OB5] & 0.603 & Quality Improvement [OB12] & 0.659 \\
Enhancement on Internal Operations [OB6] & 0.645 & Customer Satisfaction [OB31] & 0.480 \\
Enhancement of Reputation [OB7] & 0.776 & Management Control [OB14] & 0.665 \\
Improved Output [OB8] & 0.789 & & \\
\hline
\end{tabular}

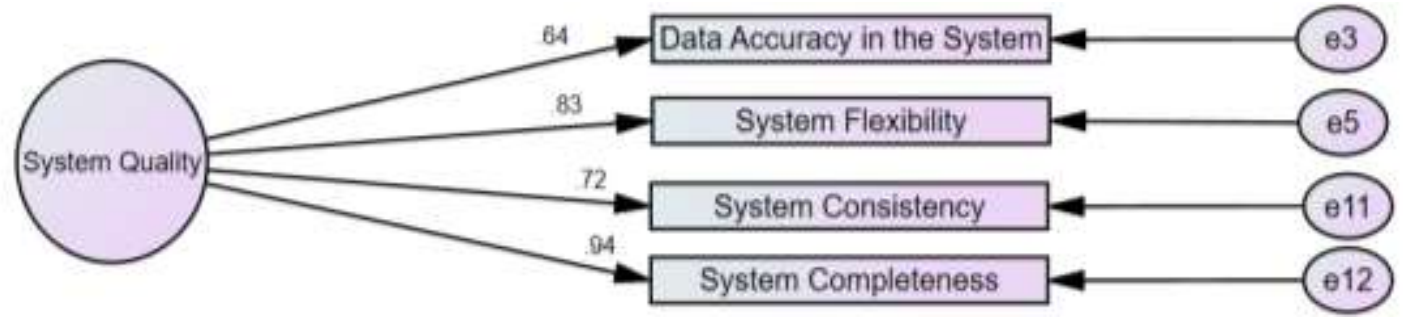

Fig. 1: Measurement model of system quality 


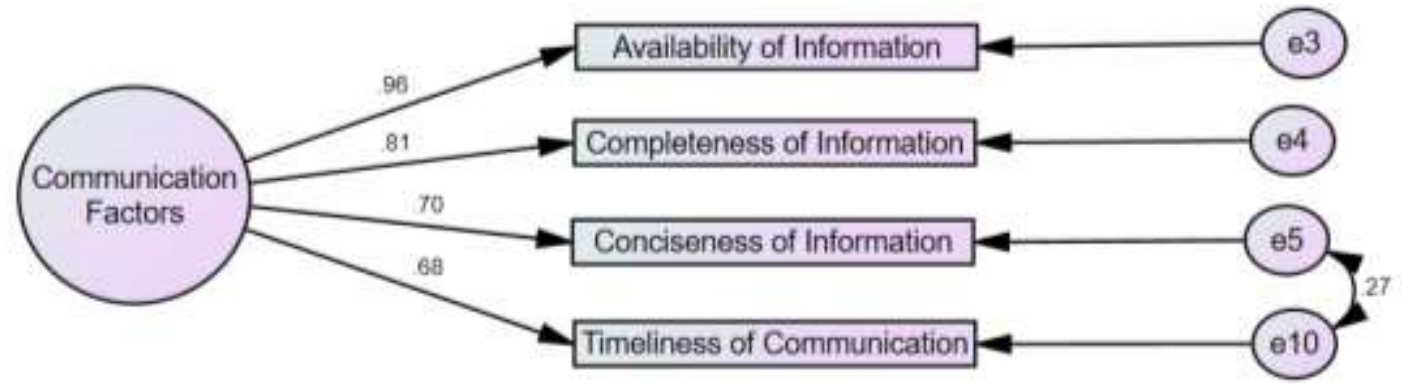

Fig. 2: Measurement model of communication quality

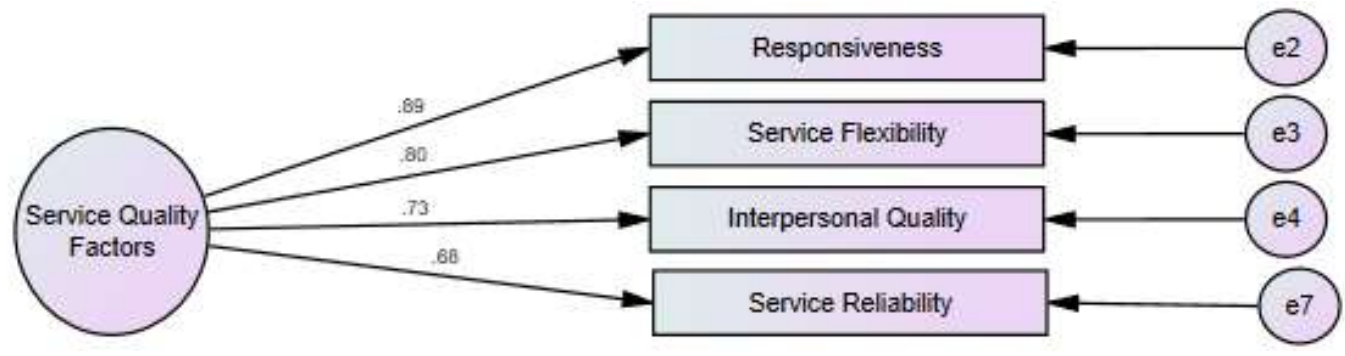

Fig. 3: Measurement model of service quality

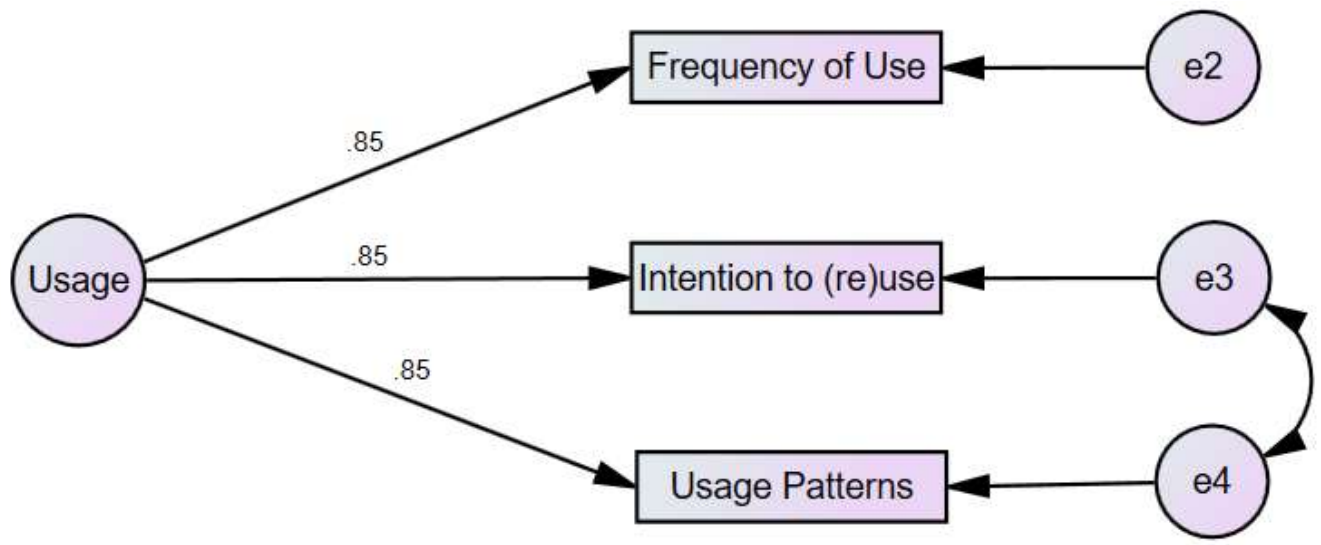

Fig. 4: Measurement model of system use factor

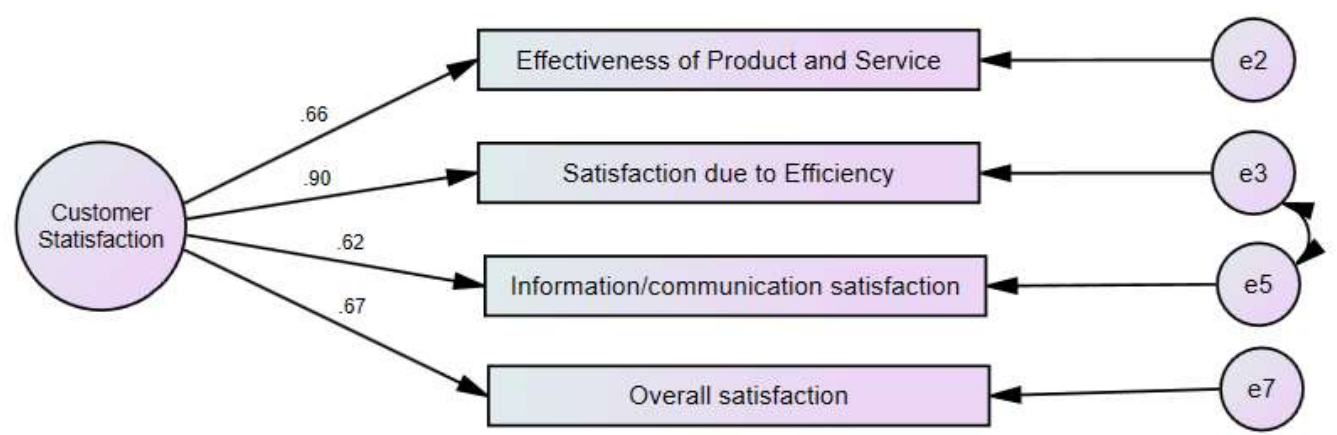

Fig. 5: Measurement model of 'satisfaction' factor 


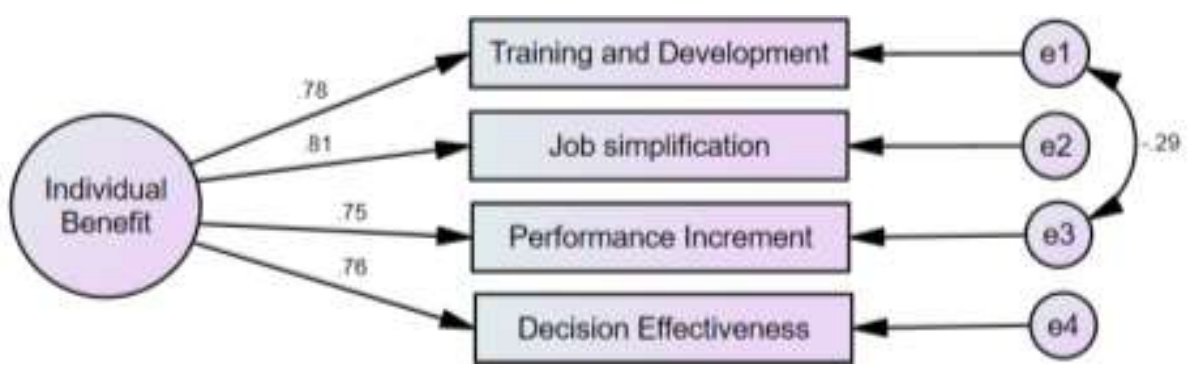

Fig. 6: Measurement model of individual benefit

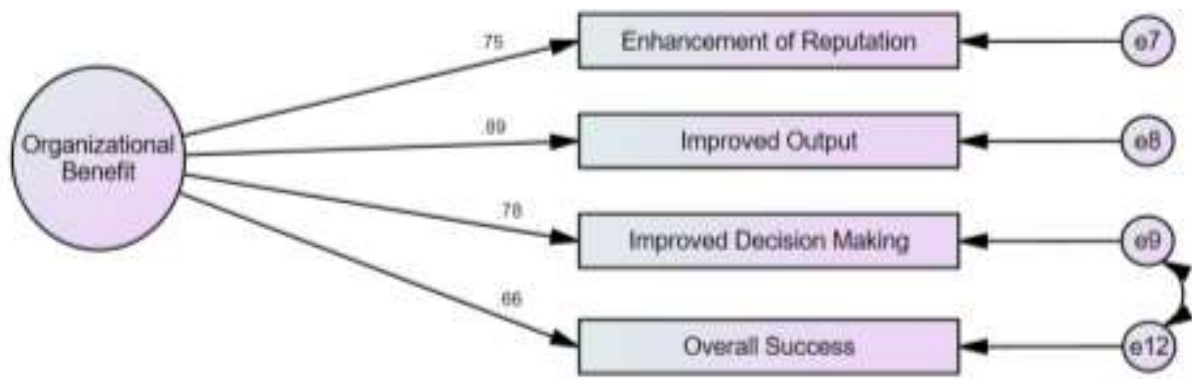

Fig. 7: Measurement model of organizational benefit

All the models for the above latent variables passed the model fit measures as per Table 10. Out of 7 variables, the model referring to system quality and Individual Benefit reached the best fit with a CFI value of 1.00 .

As per (Gaskin and Lim, 2016), model is considered excellent when the values of CMIN/DF are between 1 and 3, Comparative Fit Index (CFI) is $>0.95$, Standardized Root Mean Residual (SRMR) is $<0.08$, Root Mean Square Error of Approximation (RMSEA) is $<0.06$, PClose ( $\mathrm{p}$ value when RMSEA is $>0$ ) is $>0.05$, Composite Reliability (CR) is > 0.7 , Average Variance Extracted (AVE) is $>0.5$ and $\operatorname{MaxR}(\mathrm{H})$ (Maximal Reliability) is $>0.7$.

The values of $\mathrm{CR}, \mathrm{AVE}$ and $\operatorname{MarR}(\mathrm{H})$ in Table 11 shows that the model is reliable and valid. The validity of each critical success factor was tested using convergent validity using Average Variance Extract (AVE). Reliability was tested using Composite Reliability and Maximal Reliability and Discriminant validity could not be tested in a single factor model.

\section{Validation using Partial Least Square Regression}

Partial Least Square Multi-Factor Structural Equation Modeling was utilized to refine further and validate the success factors. SPSS AMOS doesn't have built-in features to test multicollinearity among the observed variables and Hetero-Trait-Mono-Trait ratio of correlations (HTMT) between unobserved variables. PLS-SEM is a secondgeneration multivariate analysis method that enables measurement and structural models to be analyzed together like covariance-based structural equation modeling (Civelek, 2018). Selected variables were plotted in the SmartPLS 3.0.3.

While observing the result for collinearity statistics (VIF), three variables were found to be collinear (Table 12).
All the conflicting variables were removed from the model. Similarly, one of the variables had less than 0.7 factor loading and hence, removed (Table 13).

While testing the Hetero-Trait Mono-Trait ratio (HTMT), the value of the latent variable 'organizational benefit' had crossed the recommended value and was observed to be 0.971 . Two variables- 'enhancement of reputation [OB7]' and 'quality improvement [OB12]' were found problematic and removed from the model.

The following diagram (Fig. 8) shows the model after corrective actions with critical success factors associated with it.

The resulting model has the construct reliability and validity statistics as given in Table 14 . The values of Cronbach's Alpha, rho_A, CR and AVE are greater than 0.7 for all latent variables. Composite Reliability (CR) is a measure of internal consistency calculated using structured factor loadings. Rho_A is also a composite reliability indicator computed on unstandardized loadings. Average Variance Extracted (AVE) is a measure to assess convergent validity. If there are convergent validity issues, then variables do not correlate well with each other within their parent factor.

An assessment of discriminant validity is necessary for any research which contains latent variables to prevent multicollinearity issues. Discriminant validity refers to how exactly the construct differs from each other and the extent to which it has been validated. It measures how similar the overlapping construct is. The discriminant validity can be evaluated using the Fornell-Larcker criterion and Heterotrait-monotrait (HTMT) ratio of correlation. Fornell-Lacker criterion compares the square root of the average variance extracted with the correlation of latent variables (Table 15). 


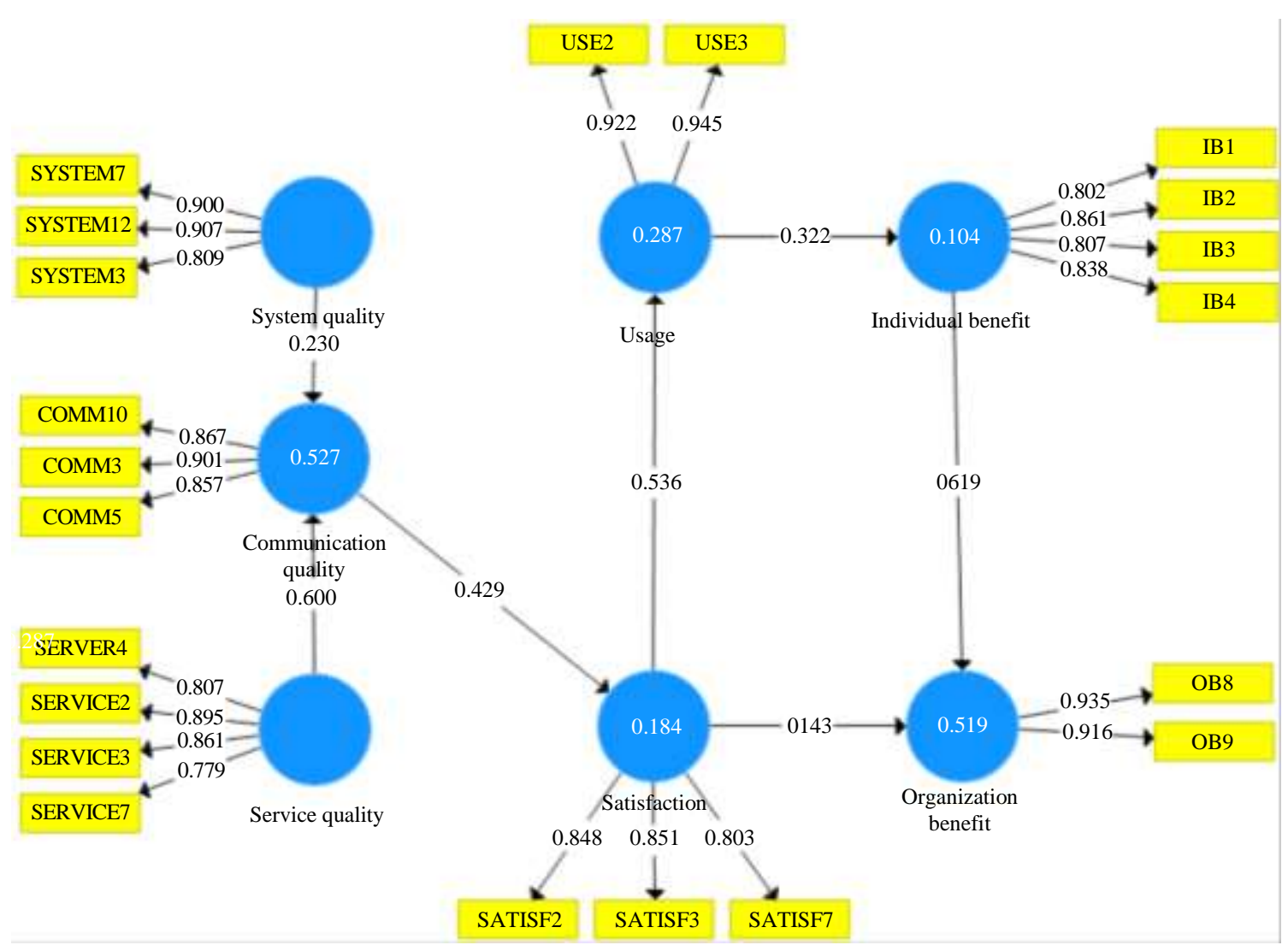

Fig. 8: Structural equation modeling for critical success factors using PLS method

Table 10: Model fit measures

\begin{tabular}{llllllll}
\hline Latent variables & CMIN & DF & CMIN/DF & CFI & SRMR & RMSEA & PClose \\
\hline System quality & 1.310 & 2.000 & 0.655 & 1.000 & 0.012 & 0.000 & 0.759 \\
Communication quality & 2.083 & 1.000 & 2.083 & 0.999 & 0.010 & 0.053 & 0.329 \\
Service quality & 3.842 & 2.000 & 1.921 & 0.997 & 0.018 & 0.049 & 0.402 \\
System use & 2.342 & 1.000 & 2.342 & 0.998 & 0.016 & 0.059 & 0.297 \\
Satisfaction & 2.105 & 1.000 & 2.105 & 0.998 & 0.018 & 0.054 & 0.326 \\
Individual benefit & 0.047 & 1.000 & 0.047 & 1.000 & 0.002 & 0.000 & 0.893 \\
Organizational benefit & 4.376 & 3.000 & 1.459 & 0.998 & 0.019 & 0.035 & 0.564 \\
\hline
\end{tabular}

Table 11: Validity and reliability measures

\begin{tabular}{llll}
\hline Latent variables & CR & AVE & MaxR(H) \\
\hline System quality & 0.869 & 0.628 & 0.925 \\
Communication quality & 0.871 & 0.633 & 0.943 \\
Service quality & 0.859 & 0.606 & 0.885 \\
System use & 0.888 & 0.725 & 0.888 \\
Satisfaction & 0.808 & 0.519 & 0.863 \\
Individual benefit & 0.857 & 0.599 & 0.858 \\
Organizational benefit & 0.856 & 0.600 & 0.882 \\
\hline
\end{tabular}

Table 12: List of variables with collinearity issue

\begin{tabular}{lllll}
\hline SN & Latent variable & Variable name & VIF & Conflicting variable \\
\hline 1 & System quality & System completeness [SYSTEM12] & 3.495 & System consistency [SYSTEM11] \\
2 & Communication quality & Availability of information [COMM3] & 3.490 & Completeness of information COMM4] \\
3 & System use & Frequency of use [USE2] & 3.610 & Usage patterns [USE4] \\
\hline
\end{tabular}

Table 13: List of variables with low factor loading

\begin{tabular}{lllll}
\hline SN & Latent variable & Variable name & Factor loading & Action \\
\hline 1 & Satisfaction & Information/communication satisfaction [SATISF5] & 0.661 & Eliminated \\
\hline
\end{tabular}


Table 14: Validity and reliability measures of CSF model

\begin{tabular}{lllll}
\hline Latent variable & Cronbach's alpha & rho_A & Composite reliability & Average Variance Extracted (AVE) \\
\hline Communication quality & 0.848 & 0.859 & 0.907 & 0.766 \\
Individual benefit & 0.846 & 0.847 & 0.897 & 0.684 \\
Organization benefit & 0.833 & 0.843 & 0.923 & 0.857 \\
Satisfaction & 0.785 & 0.803 & 0.873 & 0.696 \\
Service quality & 0.856 & 0.866 & 0.903 & 0.700 \\
System quality & 0.844 & 0.857 & 0.906 & 0.763 \\
System use & 0.854 & 0.870 & 0.931 & 0.872 \\
\hline
\end{tabular}

Table 15: Result of Fornell-Lacker criterion

\begin{tabular}{|c|c|c|c|c|c|c|c|}
\hline Latent variable & $\begin{array}{l}\text { Communication } \\
\text { quality }\end{array}$ & $\begin{array}{l}\text { Individual } \\
\text { benefit }\end{array}$ & $\begin{array}{l}\text { Organization } \\
\text { benefit }\end{array}$ & Satisfaction & $\begin{array}{l}\text { Service } \\
\text { quality }\end{array}$ & $\begin{array}{l}\text { System } \\
\text { quality }\end{array}$ & System use \\
\hline Communication quality & 0.875 & & & & & & \\
\hline Individual benefit & 0.354 & 0.827 & & & & & \\
\hline Organization benefit & 0.449 & 0.712 & 0.926 & & & & \\
\hline Satisfaction & 0.429 & 0.654 & 0.548 & 0.834 & & & \\
\hline Service quality & 0.695 & 0.362 & 0.339 & 0.607 & 0.836 & & \\
\hline System quality & 0.479 & 0.14 & 0.354 & 0.323 & 0.415 & 0.874 & \\
\hline System use & 0.213 & 0.322 & 0.275 & 0.536 & 0.404 & 0.172 & 0.934 \\
\hline
\end{tabular}

Table 16: Heterotrait-Monotrait (HTMT) ratio

\begin{tabular}{|c|c|c|c|c|c|c|c|}
\hline Latent variable & $\begin{array}{l}\text { Communication } \\
\text { quality }\end{array}$ & $\begin{array}{l}\text { Individual } \\
\text { benefit }\end{array}$ & $\begin{array}{l}\text { Organization } \\
\text { benefit }\end{array}$ & Satisfaction & $\begin{array}{l}\text { Service } \\
\text { quality }\end{array}$ & $\begin{array}{l}\text { System } \\
\text { quality }\end{array}$ & System use \\
\hline \multicolumn{8}{|l|}{ Communication quality } \\
\hline Individual benefit & 0.414 & & & & & & \\
\hline Organization benefit & 0.531 & 0.847 & & & & & \\
\hline Satisfaction & 0.488 & 0.805 & 0.649 & & & & \\
\hline Service quality & 0.802 & 0.426 & 0.399 & 0.738 & & & \\
\hline System quality & 0.569 & 0.208 & 0.430 & 0.385 & 0.480 & & \\
\hline System use & 0.240 & 0.378 & 0.321 & 0.645 & 0.469 & 0.231 & \\
\hline
\end{tabular}

Table 17: R square statistics

\begin{tabular}{lll}
\hline Dependent variables & $\mathrm{R}$ square & $\mathrm{R}$ square adjusted \\
\hline Communication quality & 0.527 & 0.524 \\
Individual benefit & 0.104 & 0.102 \\
Organization benefit & 0.519 & 0.517 \\
Satisfaction & 0.184 & 0.182 \\
System use & 0.287 & 0.285
\end{tabular}

The other measure for discriminant validity is the Heterotrait-Monotrait (HTMT) ratio of correlation. Ab Hamid et al. (2017; Henseler et al., 2015) tested the superior performance of this method using Monte Carlo simulation and found that HTMT can achieve higher specificity and sensitivity rates (97 to $99 \%$ ) compared to Fornell-Lacker (20.82\%). HTMT values close to 1 indicates a lack of discriminant validity. As per smartpls.com, if the HTMT value is below 0.90 , discriminant validity has been established between two reflective constructs. As shown in Table 16, the HTMT values are less than 0.9 and as low as 0.208 .

$\mathrm{R}$-squared is a statistical measure of how close the data are to the fitted regression line. It is the percentage of the response variable variation that is explained by a linear model. R-square indicates how much of the total variance in the dependent variable can be explained by the independent variable. The $\mathrm{R}$ Square of Dependent Variable 'Communication Quality' is 0.527, Individual Benefit is
0.104, Organization Benefit is 0.519, Satisfaction is 0.184 and System Use is 0.287 . Independent variables are 'System Quality' and 'Service Quality' (Table 17). Falk and Miller (1992) proposed that the $\mathrm{R}^{2}$ values should be equal to or greater than 0.10 so that a certain endogenous building variance is considered acceptable.

\section{Result}

Earlier studies were based on the customer perspective. However, this study was based on vendors' perspectives and identified 21 critical success factors for successful IT outsourcing in emerging markets like Nepal (Fig 9). Success factors are divided into seven categories: System Quality (data accuracy, system flexibility and system completeness); communication quality (availability of information, conciseness of information, timeliness of communication); service quality (service responsiveness, service flexibility, interpersonal quality and service reliability); system use (frequency of use and intention to use/reuse); satisfaction (satisfaction due to efficiency, the effectiveness of product and service and overall satisfaction); individual benefit (job simplification; training and development; decision effectiveness; performance increment) and organizational benefit (improved output and improved decision making). 


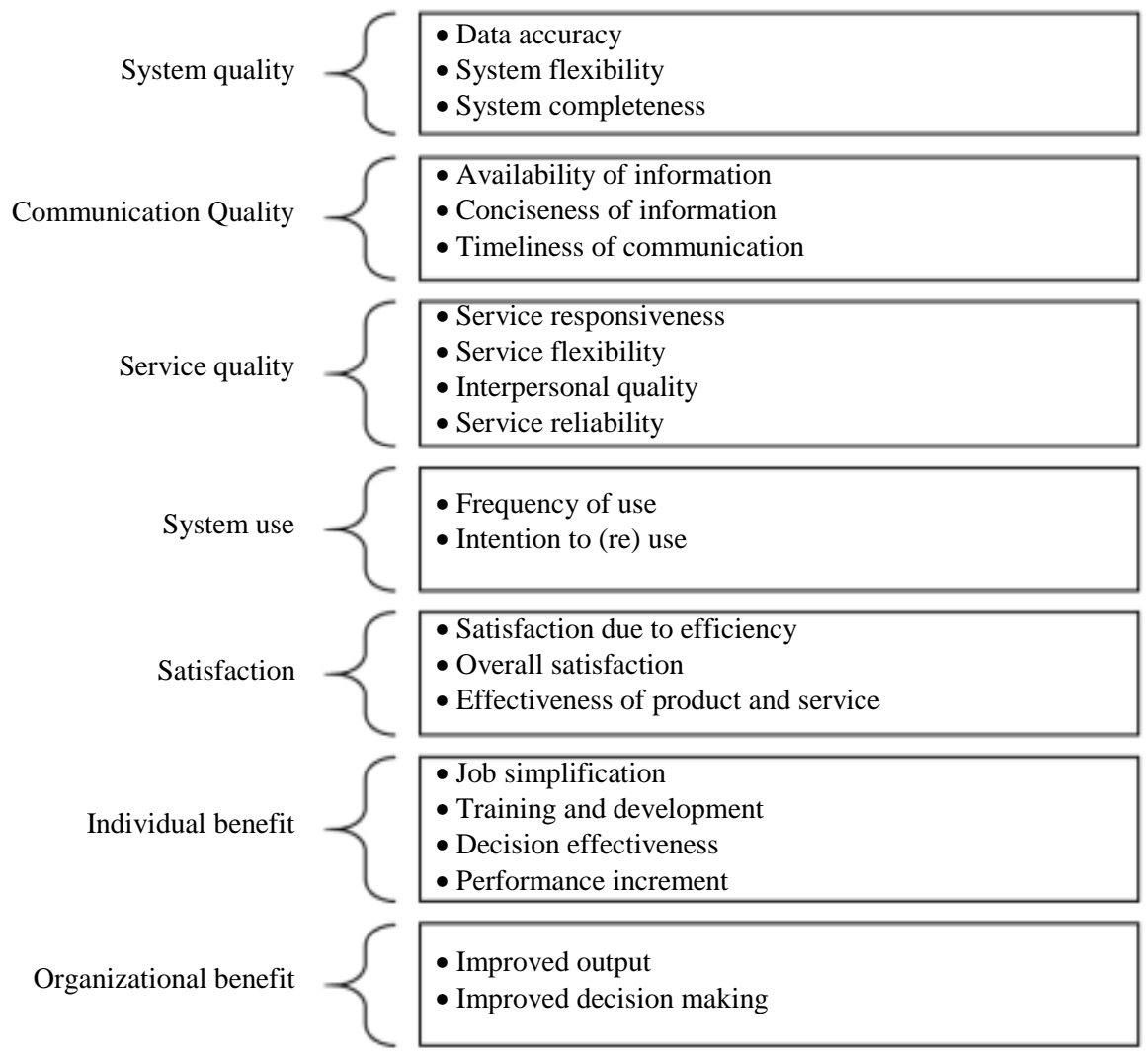

Fig. 9: Tabular representation of critical success factors of information technology outsourcing

\section{Discussion}

DeLone and McLean (2003) identified 24 success metrics under 6 categories for Ecommerce in their updated IS Success Model-systems quality (adaptability, availability, reliability, response time and usability); information quality (completeness, ease of understanding, personalization, relevance and security); service quality (assurance, empathy and responsiveness); use (nature of use, navigation patterns, number of site visits and number of transactions executed); user satisfaction (repeat purchases, repeat visits and user surveys) and net benefits (cost savings, expanded markets, incremental additional sales, reduced search costs and time savings).

Gable et al. (2008) suggested 37 variables under 4 categories in their IS-impact measurement model studied across 27 Australian Government Agencies that implemented SAP Financials in the late 90s - System quality (Data accuracy, Data currency, Database contents, Ease of use, Ease of learning, Access, User requirements, System features, System accuracy, Flexibility, Reliability, Efficiency, Sophistication, Integration and Customization); Information quality (Importance, Availability, Usability, Understandability, Relevance, Format, Content Accuracy, Conciseness, Timeliness and Uniqueness); Individual Impact (Learning, Awareness,
Decision effectiveness, Individual productivity) and Organizational Impact (Organizational costs, Staff requirements, Cost reduction, Overall productivity, Improved outcomes/outputs, Increased capacity, egovernment and Business Process Change).

McKinney et al. (2002) also separated success metrics into information quality and system quality in their study to measure the satisfaction of web-customer.

This study neither focused on the inter-relationship among observed variables nor among unobserved variables. However, the factors were observed with good construct validity indices and tested for multicollinearity.

It is recommended future researchers to identify and use more variables for 'System Use' as few variables in this category may lead to an ambiguous result. Similarly, it is advised to study 'Individual benefit' and 'Organizational benefit' as two separate variables because human behavior cannot be measured as a whole like organizational. The complex nature of IT outsourcing success requires careful attention to the definition and measurement of each independent and dependent variable.

\section{Conclusion}

This paper has made a significant contribution to identify 21 critical success factors of IT Outsourcing under 
7 categories from the viewpoint of the vendor. IT Outsourcing communities are recommended to take more focus on these factors. This paper also provides insight to the policymakers to adopt new strategies to mark their footprint in the global outsourcing industries. Similarly, the study will help researchers to expand their knowledge and use theses variables in their future studies.

\section{Author's Contributions}

Sushil Paudel: Proposed and defined the variables, carried out the research and wrote the paper.

Vinish Kumar: Supervised the research work and suggested improvements.

\section{Ethics}

The authors confirms that this article has not been published in any other journal. The corresponding author confirms that all the authors have read and approved the manuscript and there are no ethical issues involved.

\section{References}

Ab Hamid, M. R., Sami, W., \& Sidek, M. M. (2017, September). Discriminant validity assessment: Use of Fornell \& Larcker criterion versus HTMT criterion. In Journal of Physics: Conference Series (Vol. 890, No. 1, p. 012163). IOP Publishing. https://doi.org/10.1088/1742-6596/890/1/012163

Aksoy, A., Sucky, E., \& Öztürk, N. (2014). Dynamic strategic supplier selection system with fuzzy logic. Procedia-Social and Behavioral Sciences, 109 , 1059-1063. https://doi.org/10.1016/j.sbspro.2013.12.588

Almutairi, H., \& Subramanian, G. H. (2005). An empirical application of the Delone and Mclean model in the Kuwaiti private sector. Journal of Computer Information Systems, 45(3), 113-122. https://www.tandfonline.com/doi/abs/10.1080/0887 4417.2005.11645849

Bailey, J. E., \& Pearson, S. W. (1983). Development of a tool for measuring and analyzing computer user satisfaction. Management Science, 29(5), 530-545. https://doi.org/10.1287/mnsc.29.5.530

Bapna, R., Barua, A., Mani, D., \& Mehra, A. (2010). Cooperation, Coordination and Governance in Multisourcing: An Agenda for Analytical and Empirical Research. Information Systems, 21(4), 785-795. https://doi.org/10.1287/isre.1100.0328

Chang, J. C. J., \& King, W. R. (2005). Measuring the performance of information systems: A functional scorecard. Journal of Management Information Systems, 22(1), 85-115. https://doi.org/10.1080/07421222.2003.11045833
Civelek, M. E. (2018). Essentials of structural equation modeling. Essentials of Structural Equation Modeling (2018). https://papers.ssrn.com/sol3/papers.cfm?abstract_id $=3338325$

DeLone, W. H., \& McLean, E. R. (1992). Information systems success: The quest for the dependent variable. Information Systems Research, 3(1),60-95. https://doi.org/10.1287/isre.3.1.60

DeLone, W. H., \& McLean, E. R. (2003). The DeLone and McLean Model of Information Systems Success: A Ten-Year Update. Journal of Management Information Systems, 19(4), 9-30. https://doi.org/10.1080/07421222.2003.11045748

Doll, W. J., \& Torkzadeh, G. (1988). The measurement of end-user computing satisfaction. MIS Quarterly, 12(2), 258-274. https://doi.org/10.2307/248851

Erturgut, R. (2012). The Future of Supply Chain and Logistics Management in the Strategic Organizations: Contractor Companies and New Generation Suppliers. Social and Behavioral Sciences, 46, 4221-4225. https://doi.org/10.1016/j.sbspro.2012.06.230

Falk, R. F., \& Miller, N. B. (1992). A primer for soft modeling. University of Akron Press, ISBN-10: 0962262846.

Gable, G. G., Sedera, D., \& Chan, T. (2008). Reconceptualizing Information System Success: The IS-Impact Measurement Model. Journal of the Association for Information Systems, 9(7), 377-408. https://doi.org/10.17705/1jais.00164

Gartner. (2020). Retrieved from http://www.gartner.com/DisplayDocument?id=1881 $228 \&$ ref $=$ 'g_fromdoc'

Gaskin, J., \& Lim, J. (2016). Model Fit Measures. AMOS Plugin. Retrieved from Gaskination's StatWiki. http://statwiki.gaskination.com/index.php?title=Plugins

Henseler, J., Ringle, C. M., \& Sarstedt, M. (2015). A new criterion for assessing discriminant validity in variance-based structural equation modeling. Journal of the Academy of Marketing Science, 43(1), 115-135. https://doi.org/10.1007/s11747-014-0403-8

Iivari, J. (2005). An empirical test of the DeLone-McLean model of information system success. ACM SIGMIS Database: the DATABASE for Advances in Information Systems, 36(2), 8-27. https://doi.org/10.1145/1066149.1066152

Investment Board Nepal. (2017). ICT Sector Profile. Retrieved from https://ibn.gov.np/wpcontent/uploads/2020/04/ICT-Sector-Profile.pdf

Kearney, A. T. (2017). Global services location index. Accessed October, 10, 2018. 
McKinney, V., Yoon, K., \& Zahedi, F. (2002). The Measurement of Web-Customer Satisfaction: An Expectation and Disconfirmation Approach. Information Systems Research, 13(3), 296-315. https://doi.org/10.1287/isre.13.3.296.76

Pitt, L. F., Watson, R. T., \& Kavan, C. B. (1995). Service quality: A measure of information systems effectiveness. MIS Quarterly, 19(2), 173-187. https://doi.org/10.2307/249687

Rainer, R. K., Jr., \& Watson, H. J. (1995). The keys to executive information system success. Journal of Management Information Systems, 12(2), 83-98. https://doi.org/10.1080/07421222.1995.11518082

Roldan, J. L., \& Sanchez-Franco, M. J. (2012). VarianceBased Structural Equation Modeling: Guidelines for Using Partial Least Squares in Information Systems Research. (M. Mora, O. Gelman, A. Steenkamp, \& M. Raisinghani, Eds.) Research Methodologies, Innovations and Philosophies in Software Systems Engineering and Information Systems, pp. 193-221. https://doi.org/10.4018/978-1-4666-0179-6.ch010
Urbach, N., \& Muller, B. (2012). The Updated DeLone and McLean Model of Information Systems Success. In Y. K. Dwivedi, Information Systems Theory: Explaining and Predicting Our Digital Society (pp. 1-18). New York: Springer. https://doi.org/10.1007/978-1-4419-6108-2_1

World Bank Group. (2018). Creating Markets in Nepal: Country Private Sector Diagnostic. Washington, D.C.:

IFC. https://elibrary.worldbank.org/doi/abs/10.1596/31006 